\title{
ARTICLE OPEN \\ Mechanism of contact pressure-induced friction at the amorphous carbon/alpha olefin interface
}

\author{
Xiaowei Li $\mathbb{D}^{1,2}$, Aiying Wang ${ }^{2}$ and Kwang-Ryeol Lee ${ }^{1}$
}

\begin{abstract}
Combining an amorphous carbon (a-C) film with a lubricating oil can significantly improve the friction performance and lifetime of moving mechanical components. However, the friction mechanism is not well understood owing to a lack of information regarding the structure of the interface when exposed to high contact pressure. Here, we select linear alpha olefin, $\mathrm{C}_{5} \mathrm{H}_{10}$, as a lubricant and study the evolution of the structure of the $a-C / C_{5} \mathrm{H}_{10} / a-C$ sliding interface under contact pressure via reactive molecular dynamics simulation. Our results suggest that introducing $\mathrm{C}_{5} \mathrm{H}_{10}$ into the a-C/a-C interface reduces the friction coefficient by up to $93 \%$ compared with no lubricant, although the lubricating efficiency strongly depends on the contact pressure. In particular, increasing the contact pressure not only induces the binding of the lubricant with a-C, but also facilitates the dissociation of the $\mathrm{C}_{5} \mathrm{H}_{10} \mathrm{carbon}$ carbon skeleton by specific scissions, which governs the friction behavior. These results disclose the underlying lubrication mechanism and could enable the development of new and effective lubricating systems with long lifetimes.
\end{abstract}

npj Computational Materials (2018)4:53; doi:10.1038/s41524-018-0111-x

\section{INTRODUCTION}

In recent years, amorphous carbon (a-C) films have become increasingly popular in both the scientific and engineering communities because of their impressive combination of high hardness, low friction coefficient, and chemical inertness. ${ }^{1-4}$ These properties can provide effective protection against serious mechanical or chemical damage of moving mechanical components, such as tools, ${ }^{5}$ automobile engines, ${ }^{6}$ aerospace components, ${ }^{7}$ and artificial joints. ${ }^{8,9}$ However, a-C films inevitably undergo self-consumption, which severely limits their lifetime and reliability and ultimately leads to the catastrophic failure of the coated surface.

According to recent reports, the combination of a fluid lubricant (normally a base oil with additives) and an a-C film can ensure easy slippage and long wear life of the friction interface, $3,10-13$ thus significantly enhancing the anti-friction and anti-wear abilities of moving mechanical components over a long service lifetime. However, a majority of reports have focused on the antifriction and anti-wear properties of inorganic nanoparticles and organic modifiers, such as zinc dialkyldithiophosphate, ${ }^{14,15}$ tallow diethanol amine, ${ }^{16}$ glycerol mono-oleate, ${ }^{17}$ and graphene, ${ }^{18}$ incorporated in the lubricant, while the interaction between the $\mathrm{a}-\mathrm{C}$ film and base oil and the corresponding evolution of the interfacial structure during the friction process has not been given enough attention. Additionally, descriptions of the synergistic mechanism of the $\mathrm{a}-\mathrm{C}$ and fluid films are still confined to phenomenal explanations due to the highly limited experimental in-situ characterization of the microstructure of friction interface. Thus, an in-depth understanding of the friction mechanism at the atomic scale is required.

Furthermore, it is well known that the contact pressure strongly affects the friction properties of a-C films. ${ }^{2,19}$ In particular, in the case of an a-C composite with lubricating oil, changing the contact pressure can trigger the transition of the lubrication state between the $\mathrm{a}-\mathrm{C}$ and the lubricating oil from boundary lubrication to mixed and hydrodynamic lubrication according to the classical Stribeckcurve theory. ${ }^{20,21}$ Hence, exploring the friction behavior of the a-C/ lubricating oil system under different contact pressures may not only further the scientific understanding of their synergistic friction mechanism in different lubrication states, but also provide an understanding of the friction-induced structural transformation of the lubricating oil, which is indispensable for the selection and design of the base oil and the technical implementation of a-Clubricant systems.

In the present work, we performed a reactive molecular dynamics (MD) simulation using ReaxFF ${ }^{22,23}$ to study the friction behavior of a self-mated a-C film lubricated with a base oil. The linear alpha olefin $\mathrm{C}_{5} \mathrm{H}_{10}$ was considered as the representative lubricant. The dependence of the friction properties of the a-C/ $\mathrm{C}_{5} \mathrm{H}_{10}$ /a-C system on the contact pressure was investigated, and the corresponding evolution of its interfacial structure was studied to unravel the fundamental mechanism of their synergistic friction behavior. The results indicated that the friction properties were highly dependent on the contact pressure, and the low friction was attributed to the synergistic effects of both interfacial passivation and $\mathrm{C}_{5} \mathrm{H}_{10}$ hydrodynamic lubrication.

\section{RESULTS}

Observation of morphology during the friction process

Figure 1 shows the evolution of the configurations of a-C/C $\mathrm{C}_{5} \mathrm{H}_{10} / \mathrm{a}$ $\mathrm{C}$ friction systems with sliding time under contact pressures of 5 , 20 , and $50 \mathrm{GPa}$, respectively. As shown in Fig. $1 \mathrm{a}$, when the contact pressure was $5 \mathrm{GPa}$, the system contained two sharp $\mathrm{a}-\mathrm{C} / \mathrm{C}_{5} \mathrm{H}_{10}$

\footnotetext{
${ }^{1}$ Computational Science Center, Korea Institute of Science and Technology, Seoul 136-791, Republic of Korea and ${ }^{2}$ Key Laboratory of Marine Materials and Related Technologies, Zhejiang Key Laboratory of Marine Materials and Protective Technologies, Ningbo Institute of Materials Technology and Engineering, Chinese Academy of Sciences, Ningbo 315201, P.R. China

Correspondence: Xiaowei Li (lixw0826@gmail.com) or K-R. Lee (krlee@kist.re.kr)
}

Received: 14 May 2018 Revised: 4 September 2018 Accepted: 11 September 2018

Published online: 26 September 2018 

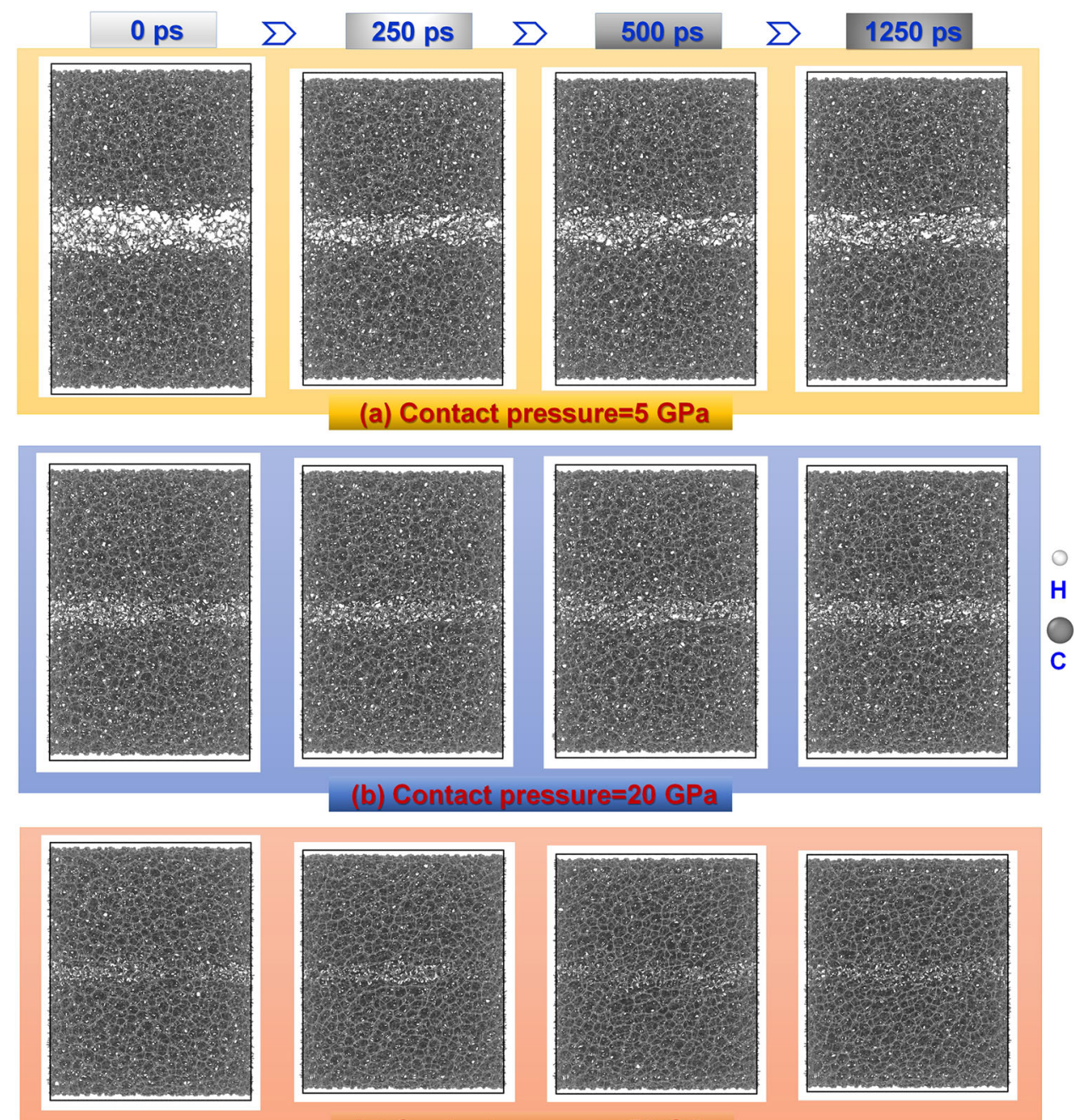

(c) Contact pressure $=50 \mathrm{GPa}$

Fig. 1 Configurations of a-C/C ${ }_{5} \mathrm{H}_{10} / \mathrm{a}-\mathrm{C}$ friction systems at contact pressures of a $5, \mathbf{b} 20$, and c $50 \mathrm{GPa}$

interfaces with locally mixed atoms after the loading process at $0 \mathrm{ps}$. From 0 to $1250 \mathrm{ps}$, the atomic movement at the interface was enhanced, and the sharp interface became somewhat fuzzy and eventually transformed into a steady-state friction interface. In particular, a fraction of the $\mathrm{C}_{5} \mathrm{H}_{10}$ molecules were still located at the central position and did not interact with the $\mathrm{a}-\mathrm{C}$ structures (Fig. 1a). However, as the contact pressure was increased to 20 and $50 \mathrm{GPa}$ (Fig. 1b,c), more atoms diffused across the interface, resulting in greater interaction between the a-C film and $\mathrm{C}_{5} \mathrm{H}_{10}$ lubricant. Hence, the initially observed sharp a-C/ $\mathrm{C}_{5} \mathrm{H}_{10}$ interfaces could not be distinguished. A severe structural distortion occurred, suggesting the presence of high residual compressive stress at the interface. In addition, the system required a long time for the running-in process to reach the steady state because of the drastic mixing at the interface, as will be confirmed later.

Friction with respect to contact pressure for the $a-C / C_{5} H_{10} / a-C$ system

The changes in contact pressure, temperature, kinetic energy (KE), and potential energy (PE) with sliding time during the friction process are plotted in Fig. 2a. First, the specified contact pressure was achieved for each case. The changes in temperature, $\mathrm{KE}$, and $\mathrm{PE}$, which increase as a function of contact pressure, confirmed the duration of the running-in processes. However, Fig. $2 b$ clearly shows that the average temperature at the steady-state friction stage increased with contact pressure following a strong fluctuation (see error bars in Fig. 2b); the average temperatures were $304 \pm 3 \mathrm{~K}$ at $5 \mathrm{GPa}, 317 \pm 6 \mathrm{~K}$ at $20 \mathrm{GPa}$, and $519 \pm 44 \mathrm{~K}$ at $50 \mathrm{GPa}$. The flash temperature between both surface asperities can be estimated using the following equation: $:^{2,24}$

$\Delta \mathrm{T}=\frac{\mu W v}{8 a K_{\mathrm{a}-\mathrm{c}}}$

where $\Delta T$ is the rise of the flash temperature at the contact between the asperities; $\mu, W$, and $v$ are the friction coefficient, applied load, and sliding velocity, respectively; $a$ is the radius of the real contact area, and $K_{\mathrm{a}-\mathrm{c}}$ is the thermal conductivity of the aC material. According to Eq. (1), as the sliding velocity was fixed at $10 \mathrm{~m} / \mathrm{s}$ for each case, the change in the flash temperature should be dominated by the friction force, as will be discussed later. Moreover, compared to the lubricant-free system (Fig. 2b), the introduction of the $\mathrm{C}_{5} \mathrm{H}_{10}$ lubricant suppressed the increase in the temperature at the a-C/a-C friction interface at low contact pressures ( 5 and $20 \mathrm{GPa}$ ), while it unexpectedly increased at a high contact pressure $(50 \mathrm{GPa})$, suggesting the presence of strong interactions between the a-C and the $\mathrm{C}_{5} \mathrm{H}_{10}$ lubricant, such as bond breaking and dissociation of $\mathrm{C}_{5} \mathrm{H}_{10}$ molecules. The changes in $\mathrm{PE}$ and $\mathrm{KE}$ with the contact pressure were also consistent with that of the temperature.

Figure $2 c$ shows the evolution of the friction force and load curves with sliding time during the friction process. In each case, 

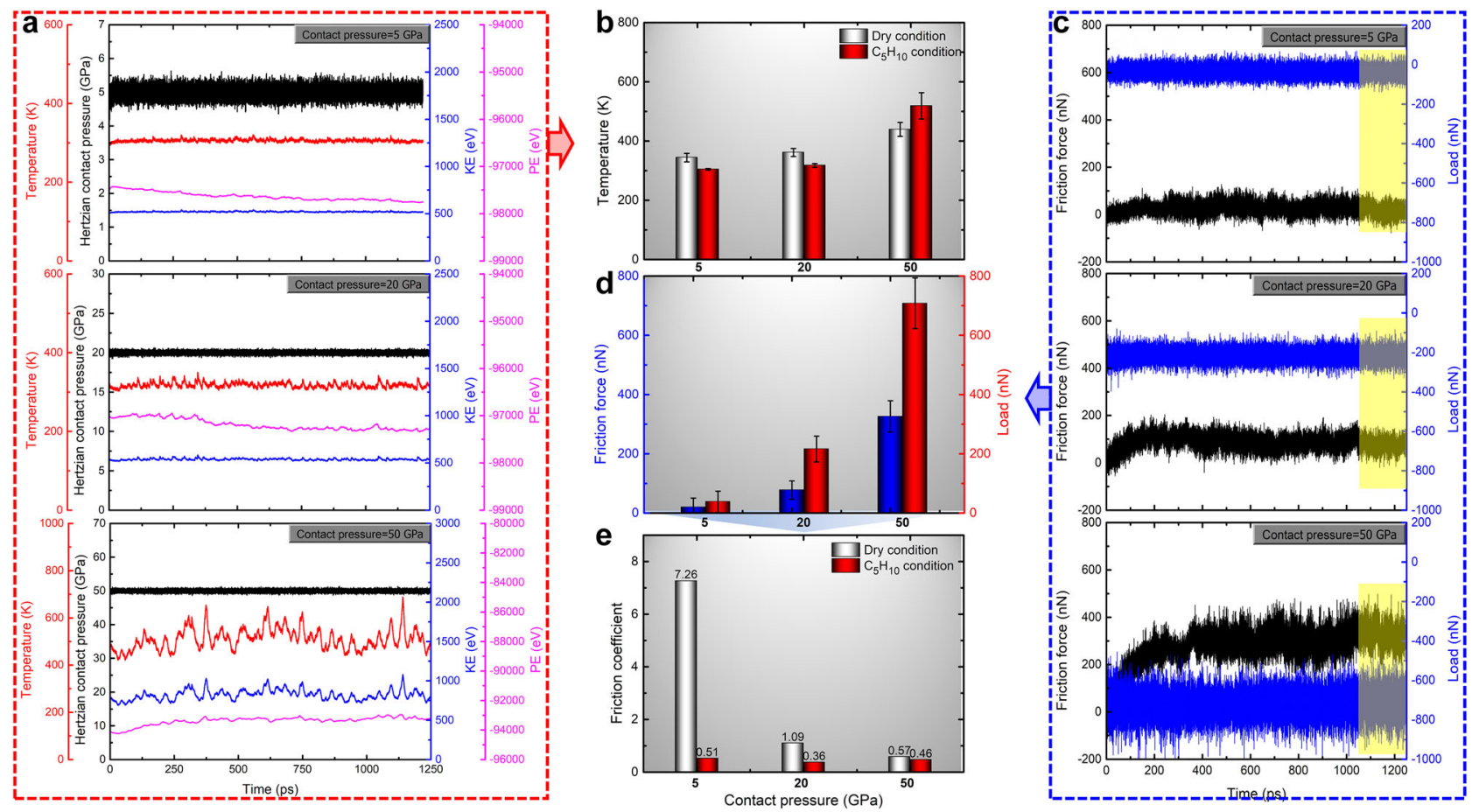

Fig. 2 Friction results with respect to contact pressure for the $\mathrm{a}-\mathrm{C} / \mathrm{C}_{5} \mathrm{H}_{10} / \mathrm{a}-\mathrm{C}$ system. a Evolution of the contact pressure, temperature, $\mathrm{KE}$, and PE with sliding time for each case. $\mathbf{b}$ Average temperature of the free layer during the steady-state friction stage as a function of contact pressure. c Evolution of the friction force and load curves with sliding time for each case. $\mathbf{d}$ Average friction force and load, and e friction coefficient as a function of contact pressure. For comparison, the results for the pure a-C/a-C system without the $\mathrm{C}_{5} \mathrm{H}_{10}$ lubricant were also considered. Error bars were standard deviations

the stable friction stage could be achieved after a sliding time of 1250 ps. The durations of the running-in process were further confirmed, and were consistent with the changes in the temperature and energies shown in Fig. 2a. In order to evaluate the dependence of friction on contact pressure, the friction force and load values during the last 200 ps (yellow region in Fig. 2c) were considered separately to compute the average friction force and load during the stable friction process, as illustrated in Fig. $2 \mathrm{~d}$. It can be noted that as the contact pressure increased from 5 to $50 \mathrm{GPa}$, the average friction force increased drastically. The rapid increase in temperature (Fig. 2b) can be explained by Eq. (1); the load also showed a trend similar to that of the friction force. However, different rates of increase of the average friction force and load with contact pressure were observed, leading to distinct changes in the friction coefficient, as shown in Fig. 2e. For comparison, the results of the pure $\mathrm{a}-\mathrm{C} / \mathrm{a}-\mathrm{C}$ system without the $\mathrm{C}_{5} \mathrm{H}_{10}$ lubricant were also considered. When the contact pressure was increased from 5 to $50 \mathrm{GPa}$, the friction coefficient first decreased and then increased, following the general intrinsic shape of a Stribeck curve; ${ }^{21,25}$ the minimum friction coefficient of 0.36 was obtained for the friction system at $20 \mathrm{GPa}$. Most importantly, compared to dry conditions, the use of $\mathrm{C}_{5} \mathrm{H}_{10}$ as a lubricant drastically improved the friction properties of the a-C film. However, when the contact pressure was $5 \mathrm{GPa}$, the friction coefficient was reduced by $93 \%$, while a reduction of only $19 \%$ was observed at a contact pressure of $50 \mathrm{GPa}$, suggesting that the anti-friction efficiency of $\mathrm{C}_{5} \mathrm{H}_{10}$ was strongly dependent on the contact state between the two sliding a-C films.

Definition of the sliding interface and intrinsic region

In order to clarify the relationship between the friction behavior and contact pressure, the friction-induced evolution of the structural properties must be analyzed. Therefore, the atomic distributions of a-C and the $\mathrm{C}_{5} \mathrm{H}_{10}$ lubricant and the evolution of the structural properties of the a-C/ $\mathrm{C}_{5} \mathrm{H}_{10} / \mathrm{a}-\mathrm{C}$ system along the $z$ direction were first evaluated (Fig. 3). Based on the atomic distributions and structural properties along the $z$ direction, the system can be divided into three layers in each case: the bottom intrinsic a-C, upper intrinsic $a-C$, and interfacial layers. At a low contact pressure of 5 or $20 \mathrm{GPa}$ (Fig. 3a, b), variations in the atom number, density, residual stress, and coordination number with sliding time were mainly observed in the interfacial layer rather than the bottom and upper intrinsic a-C layers. However, at a contact pressure of $50 \mathrm{GPa}$ (Fig. 3c), all the layers showed obvious transitions in their structural properties. In addition, the width of the interfacial layer decreased with increasing contact pressure, ranging from $18 \AA$ at $5 \mathrm{GPa}$ to $15 \AA$ at $20 \mathrm{GPa}$ and $12 \AA$ at $50 \mathrm{GPa}$. In order to investigate the effect of contact pressure on the a-C/ $\mathrm{C}_{5} \mathrm{H}_{10}$ /a-C system, the interface (gray region in Fig. 3 ), bottom intrinsic a-C (green region in Fig. 3 with a thickness of $12 \AA$ ), and upper intrinsic a-C (blue region in Fig. 3 with a thickness of $12 \AA$ ) regions were defined separately for each case to quantify their structure and properties.

Evolution of structural properties with sliding time in each case The dependence of the density, residual stress, and hybridized structure of the bottom intrinsic a-C layer on sliding time in the a$\mathrm{C} / \mathrm{C}_{5} \mathrm{H}_{10}$ /a- $\mathrm{C}$ system at different contact pressures is summarized in Fig. 4. First, the evolution of the structural properties of the bottom intrinsic a-C layer was consistent with that of the upper layer (see Figure S1 of Supplementary Information). During the sliding process, almost no changes were observed in the structure and properties with sliding time at the low contact pressures of 5 and $20 \mathrm{GPa}$. However, when the contact pressure was increased to $50 \mathrm{GPa}$, the density, residual compressive stress, and $\mathrm{sp}^{3}-\mathrm{C}$ fraction as a function of sliding time increased significantly, accompanied by a drop in the $\mathrm{sp}^{2}-\mathrm{C}$ and $\mathrm{sp}-\mathrm{C}$ fractions. This indicated that a high contact pressure could induce a strong $\mathrm{sp}^{2}$-to-sp ${ }^{3}$ 
a
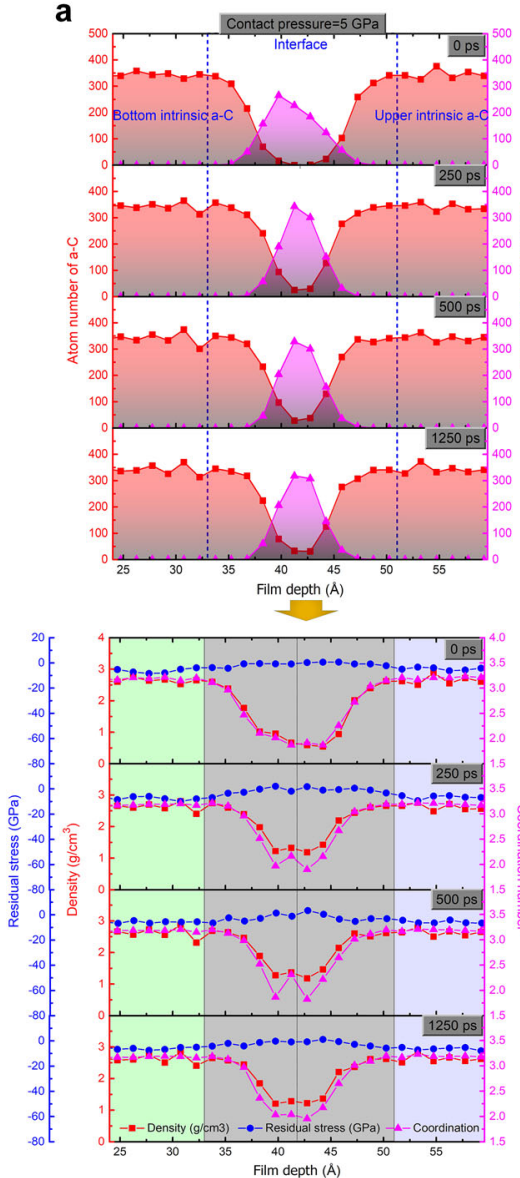

b

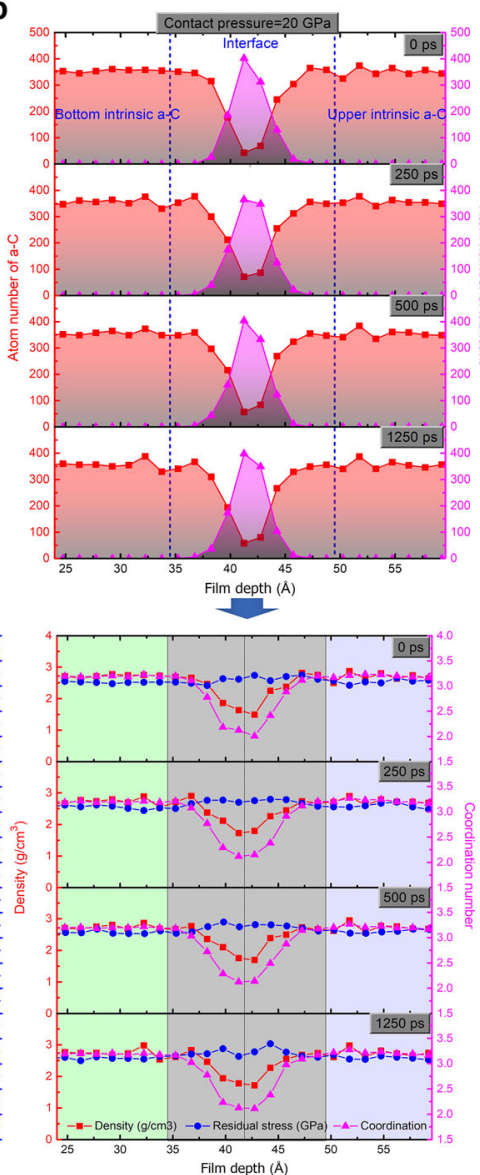

C
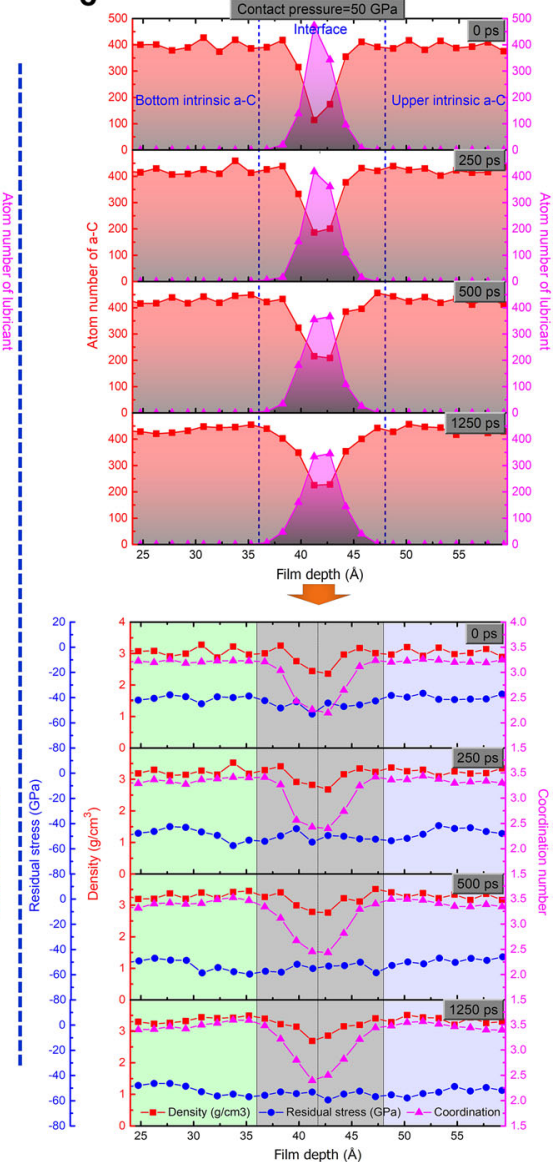

Fig. 3 Atomic distributions of a-C and the $\mathrm{C}_{5} \mathrm{H}_{10}$ lubricant, and the evolution of structural properties along the $z$ direction for the a-C/ $\mathrm{C}_{5} \mathrm{H}_{10} / \mathrm{a}-$ C system at contact pressures of a $5, \mathbf{b} 20$, and c $50 \mathrm{GPa}$, respectively
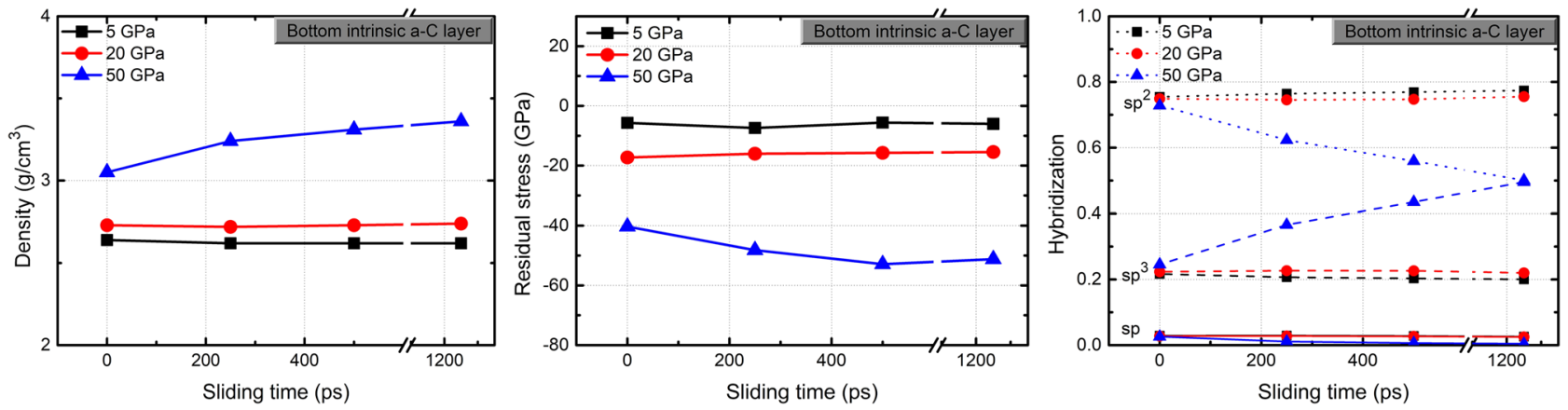

Fig. 4 Dependence of the density, residual stress, and hybridized structure of the bottom intrinsic a-C layer on sliding time in a-C/C $\mathrm{C}_{5} \mathrm{H}_{10} / \mathrm{a}-\mathrm{C}$ system at different contact pressures

transformation according to the $P-T$ phase diagram, ${ }^{26,27}$ which could improve the wear-resistance of the a-C films; however, the coated surface could also potentially be exfoliated due to the high residual stress. The interfacial layer also showed behavior similar to that of the bottom a-C layer (see Figure S2 of Supplementary Information). Friction behavior is known to be strongly related to the structure and properties of the interfacial layer. However, since the interface is composed of a-C and $\mathrm{C}_{5} \mathrm{H}_{10}$ lubricant, before characterizing the structure and properties of friction interface, it must first be determined whether the a-C film binds with the $\mathrm{C}_{5} \mathrm{H}_{10}$ lubricant. These characterizations are a prerequisite to clarify the friction mechanism of the $\mathrm{a}-\mathrm{C} / \mathrm{C}_{5} \mathrm{H}_{10} / \mathrm{a}-\mathrm{C}$ system at different contact pressures.
Information on the binding of $\mathrm{C}_{5} \mathrm{H}_{10}$ with a- $\mathrm{C}$ surface

Figure 5 shows the contribution of the $\mathrm{C}_{5} \mathrm{H}_{10}$ lubricant to the coordination number of the a-C structure and the final morphologies of the separated a-C or $\mathrm{C}_{5} \mathrm{H}_{10}$ lubricant in the $\mathrm{a}-\mathrm{C} / \mathrm{C}_{5} \mathrm{H}_{10} / \mathrm{a}-\mathrm{C}$ system after the friction process. The number of intact $\mathrm{C}_{5} \mathrm{H}_{10}$ molecules and the bonding ratio of each $C$ atom in the $\mathrm{C}_{5} \mathrm{H}_{10}$ lubricant are also evaluated in Fig. 6 . The bonding ratio, $B_{\mathrm{ab}}$, is defined as follows:

$B_{a b}=\frac{N_{a b}^{t}}{N_{a b}^{0}}$

where $N_{\mathrm{ab}}{ }^{\mathrm{t}}$ is the total bond number of atom $a$ contributed by atom $b$ when the sliding time is $t ; N_{\mathrm{ab}}{ }^{0}$ is the total bond number of 

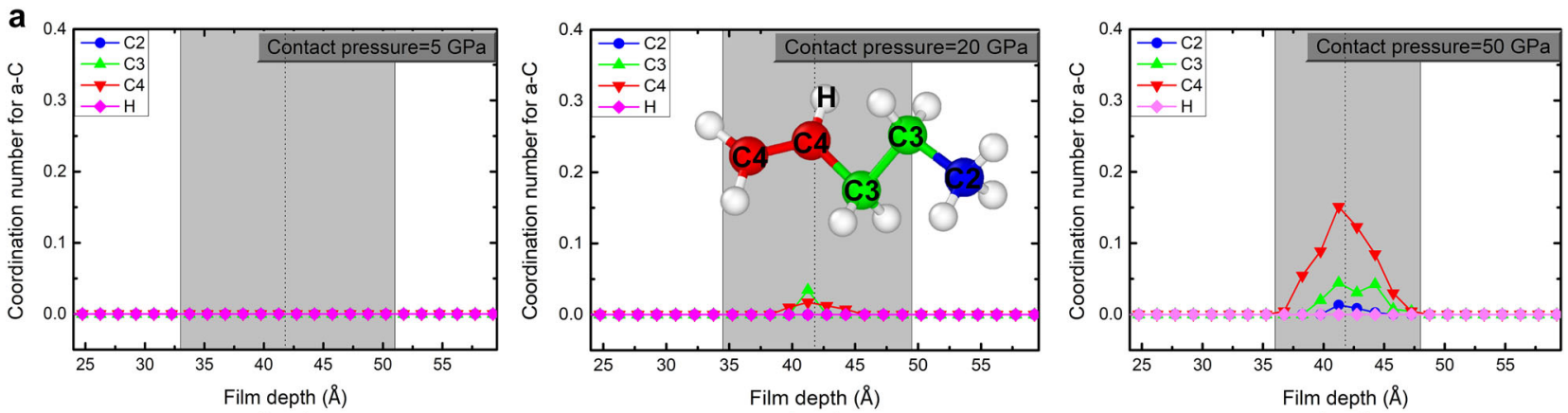

b
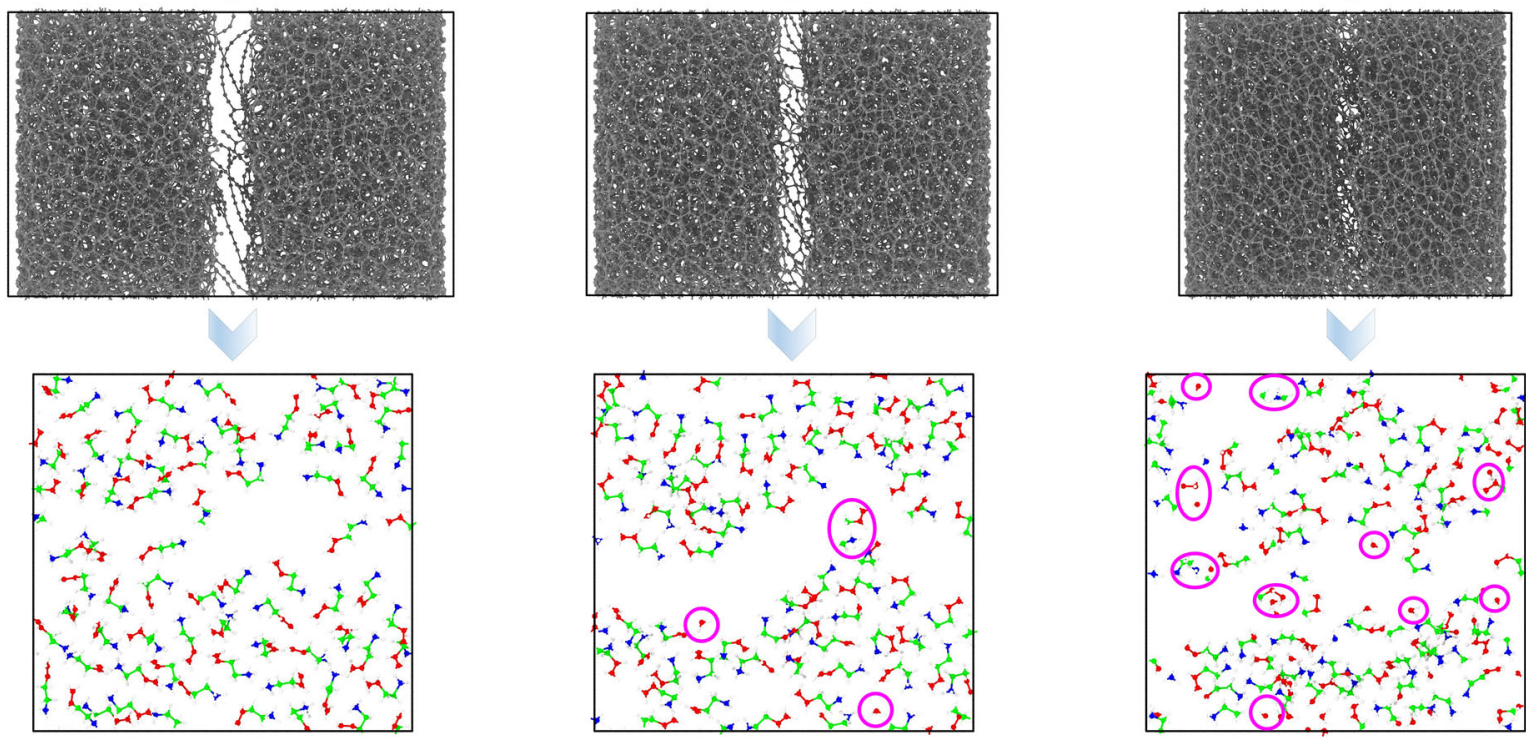

Fig. 5 Information at the a-C/ $\mathrm{C}_{5} \mathrm{H}_{10}$ friction interface. $\mathbf{a}$ Contribution of the $\mathrm{C}_{5} \mathrm{H}_{10}$ lubricant to the coordination number of the a- $\mathrm{C}$ structure; $\mathbf{b}$ $\mathrm{a}-\mathrm{C}$ and $\mathrm{c} \mathrm{C}_{5} \mathrm{H}_{10}$ lubricant structures in the $\mathrm{a}-\mathrm{C} / \mathrm{C}_{5} \mathrm{H}_{10} / \mathrm{a}-\mathrm{C}$ system after the friction process at different contact pressures
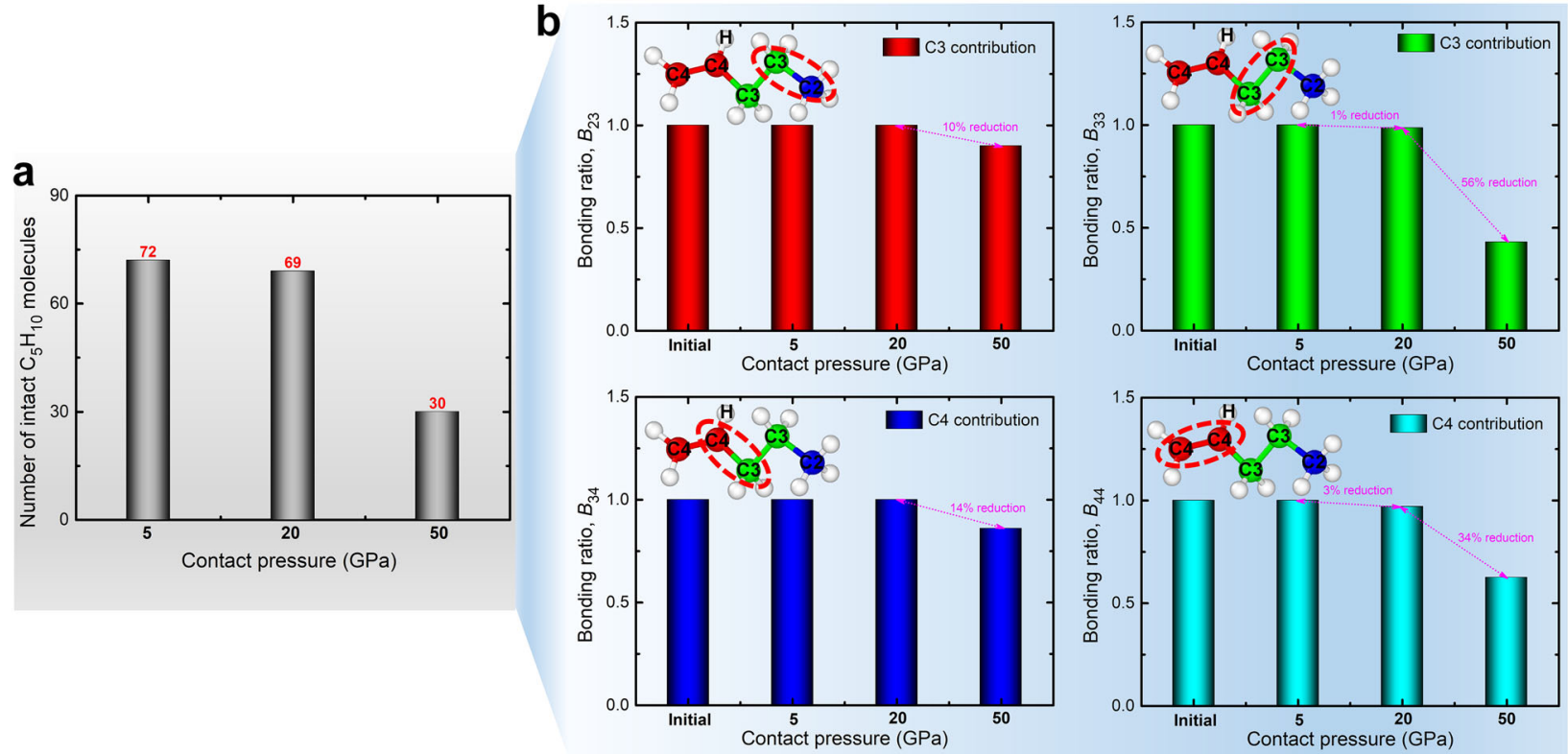

Fig. 6 Dissociation of $\mathrm{C}_{5} \mathrm{H}_{10}$ lubricant. a Number of intact $\mathrm{C}_{5} \mathrm{H}_{10}$ molecules and $\mathbf{b}$ bonding ratio for each of the $\mathrm{C}-\mathrm{C}$ bonds of $\mathrm{C}_{5} \mathrm{H}_{10}$ after the friction process, in which only the contribution from the lubricant is considered 

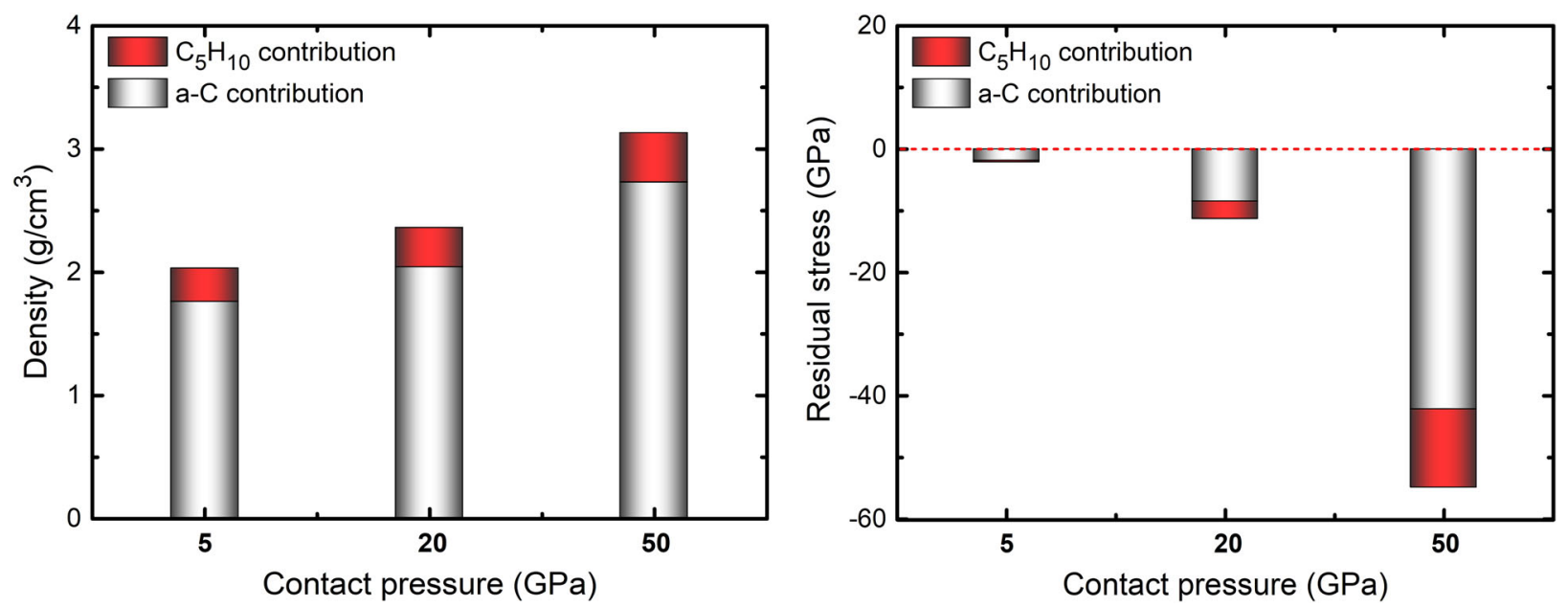

Fig. 7 Contact pressure dependence of the density and residual stress of the interface contributed by a-C and the $\mathrm{C}_{5} \mathrm{H}_{10}$ lubricant, respectively, after the friction process

atom $a$ contributed by atom $b$ when the sliding time is 0 ps; $a$ and $b$ range from atom $\mathrm{C} 2$ to $\mathrm{C} 3$ and $\mathrm{C} 4$ in the $\mathrm{C}_{5} \mathrm{H}_{10}$ molecules. With increasing contact pressure, the contribution of $\mathrm{C}_{5} \mathrm{H}_{10}$ to the coordination number of the $\mathrm{a}-\mathrm{C}$ structure obviously increased. As shown in Fig. $5 \mathrm{a}$, when the contact pressure was $5 \mathrm{GPa}$, the $\mathrm{C}_{5} \mathrm{H}_{10}$ molecules made no contribution to the coordination number of the a-C structure, suggesting that there was no chemical bonding between the $\mathrm{a}-\mathrm{C}$ and $\mathrm{C}_{5} \mathrm{H}_{10}$ molecules but instead only intermolecular interactions. Figure $3 a$ also reveals that the $\mathrm{C}_{5} \mathrm{H}_{10}$ molecules were mainly distributed at the center of the interface to form a $\mathrm{C}_{5} \mathrm{H}_{10}$ plateau region with a width of $3 \AA$, which could effectively inhibit chemical interactions between the bottom and upper a-C surfaces, as shown in Fig. $5 \mathrm{~b}$. In addition, there was no change in the number of intact $\mathrm{C}_{5} \mathrm{H}_{10}$ molecules, as illustrated in Figs. $5 \mathrm{c}$ and $6 \mathrm{a}$. This can be treated as a hydrodynamic lubrication state according to the Stribeck-curve theory. ${ }^{21}$ When the contact pressure was increased to $20 \mathrm{GPa}$, the chemical interaction between the two a-C surfaces was further enhanced (Fig. 5b), and the dissociation of a few $\mathrm{C}_{5} \mathrm{H}_{10}$ molecules (Figs. $5 \mathrm{c}$ and $6 \mathrm{a}$ ) occurred; the fragments generated by the dissociated $\mathrm{C}_{5} \mathrm{H}_{10}$ could bond with the $\mathrm{a}-\mathrm{C}$ surface, thus contributing to the coordination number of the a-C structure (Fig. $5 \mathrm{a}$ ). In particular, it should be noted that the increased coordination number of a-C mainly originated from the $\mathrm{C} 4$ and $\mathrm{C} 3$ atoms of $\mathrm{C}_{5} \mathrm{H}_{10}$. Compared with the initial values in Fig. $6 \mathrm{~b}$, the bonding ratios of the $\mathrm{C} 3-\mathrm{C} 3$ and $\mathrm{C} 4-\mathrm{C} 4$ bonds decreased by 1 and 3\%, respectively, indicating that the scission of carbon-carbon backbones mainly occurred at the $-\mathrm{CH}_{2}-\mathrm{CH}_{2}-$ and $-\mathrm{CH}=\mathrm{CH}_{2}$ sites. However, most of the intact $\mathrm{C}_{5} \mathrm{H}_{10}$ molecules remained at the center of the interface throughout the intermolecular interactions, corresponding to a mixed lubrication state. $^{21}$

When the contact pressure was further increased to $50 \mathrm{GPa}$, the bottom a-C layer strongly bonded with the upper a-C layer (Fig. 5), and the temperature at the friction interface reached up to $519 \pm$ $44 \mathrm{~K}$, leading to the severe dissociation (58\%) of the $\mathrm{C}_{5} \mathrm{H}_{10}$ molecules (Fig. 6a) and thus reaching the boundary lubrication state. $^{21}$ This dissociation was mainly achieved through further scission at the $-\mathrm{CH}=\mathrm{CH}_{2}$ and $-\mathrm{CH}_{2}-\mathrm{CH}_{2}$ - sites, with 34 and $56 \%$ reductions in their bond number, respectively, although reductions of $10 \%$ for $-\mathrm{CH}_{2}-\mathrm{CH}_{3}$ and $14 \%$ for $-\mathrm{CH}_{2}-\mathrm{CH}=$ were also observed. Large amounts of these fragments, which are displayed in Fig. $5 c$ (pink circles), recombined with the $a-C$ surface. This resulted in a drastic increase in the coordination number of a-C (Fig. 5a), which also arose mainly from the C4 and C3 atoms of the $\mathrm{C}_{5} \mathrm{H}_{10}$ lubricant. In addition, Erdemir et al. $^{3}$ reported that during the friction process, the dehydrogenation of linear olefins at the friction interface was facilitated by the catalytic action of the $\mathrm{Cu}$ films. However, no dehydrogenation was observed in the present work (see Figure S3 of Supplementary Information) due to the absence of catalytic action at the friction surface.

\section{Dependence of the interfacial properties on contact pressure}

The density and stress at the interface, which are contributed by the a- $\mathrm{C}$ and $\mathrm{C}_{5} \mathrm{H}_{10}$ lubricant, respectively, were investigated, and the results are illustrated in Fig. 7. When the contact pressure was increased from 5 to 20 and $50 \mathrm{GPa}$, the density of a-C increased gradually due to the enhanced interaction between the bottom and upper intrinsic a-C layers, while the contribution of $\mathrm{C}_{5} \mathrm{H}_{10}$ to the density also increased, which contributed to the reduction of the interfacial volume at a high contact pressure. The contribution of the $\mathrm{C}_{5} \mathrm{H}_{10}$ or a-C structures to the residual stress also increased obviously due to the highly distorted a-C structure and $\mathrm{C}_{5} \mathrm{H}_{10}$ dissociation. Compared to the lubricant-free conditions, (see Figure S4 of Supplementary Information), the introduction of $\mathrm{C}_{5} \mathrm{H}_{10}$ lubricant into the a-C/a-C interface lowered both the density and residual stress of the friction interface; however, at the high contact pressure of $50 \mathrm{GPa}$, this difference was diminished by the dissociation and recombination of $\mathrm{C}_{5} \mathrm{H}_{10}$ molecules.

Evolution of the interfacial structure with contact pressure to determine the friction mechanism

In order to explore the friction mechanism, the hybridized structure of the $C$ atoms at the interface and the mean square displacement (MSD) of the $\mathrm{C}_{5} \mathrm{H}_{10}$ lubricant were calculated separately (Fig. 8). The MSD is an essential tool to evaluate the mobility of the $\mathrm{C}_{5} \mathrm{H}_{10}$ molecules, which was estimated using the following equation:

$\operatorname{MSD}=r^{2}(t)=\frac{1}{N} \sum_{i=1}^{N}\left|r_{i}(t)-r_{i}(0)\right|^{2}$

where $N$ is the number of $i$ atoms in the system, $r_{i}(t)$ is the position of the ith atom at time $t$, and $r_{i}(0)$ is the position of the ith atom at $t=0$. At a contact pressure of $5 \mathrm{GPa}$, the friction system operated via the hydrodynamic lubrication of the $\mathrm{C}_{5} \mathrm{H}_{10}$ molecules, leading to a lower friction coefficient compared to that of the system without lubricant. When the contact pressure was increased to $20 \mathrm{GPa}$, there was no change in the $\mathrm{sp}^{3}$ fraction, but the $\mathrm{sp}^{2}$ fraction increased while the $\mathrm{sp}$ fraction decreased. This change 
a

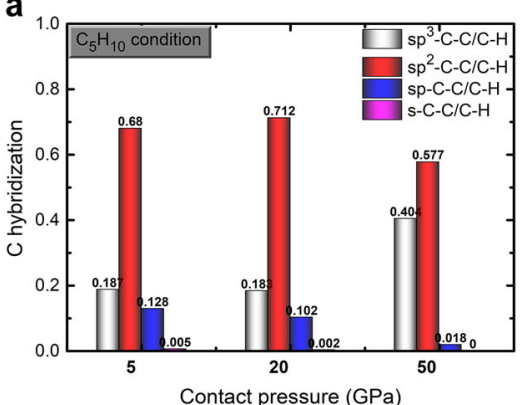

b

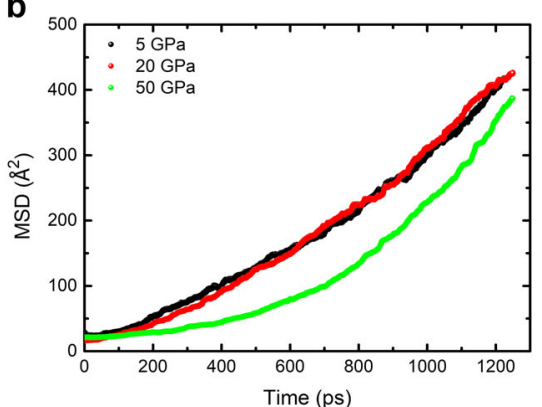

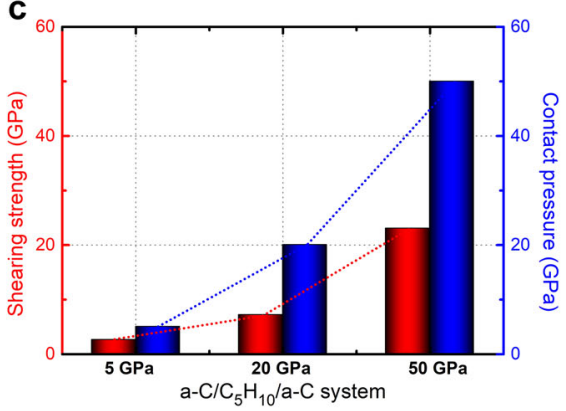

Fig. 8 Evolution of the interfacial structure with contact pressure. a Hybridized structure of the $C$ atoms at the interface as a function of contact pressure after the friction process. b MSD of the $\mathrm{C}_{5} \mathrm{H}_{10}$ molecules in the a-C/C $\mathrm{C}_{5} \mathrm{H} / \mathrm{a}-\mathrm{C}$ systems. c Shearing strength as a function of contact pressure

resulted from the interaction between the two a-C layers and the dissociation of a few $\mathrm{C}_{5} \mathrm{H}_{10}$ molecules, which passivated the dangling bonds at the interface. In particular, Fig. $8 \mathrm{~b}$ shows that the MSD at a contact pressure of $20 \mathrm{GP}$ showed almost no change from that at $5 \mathrm{GPa}$, although a few $\mathrm{C}_{5} \mathrm{H}_{10}$ molecules were dissociated. The shearing strength, $S$, is shown in Fig. $8 \mathrm{c}$ as a function of contact pressure during the steady-state friction process, and was calculated as follows:

$\mu=\frac{\mathrm{S}}{\sigma}$

where $S$ is the shearing strength (GPa) and $\sigma$ is the Hertzian contact pressure (GPa). Hence, the synergistic effect of both the passivation of dangling bonds and $\mathrm{C}_{5} \mathrm{H}_{10}$ hydrodynamic lubrication lowered the rate of increase of the shearing strength with increasing contact pressure (Fig. 8c), accounting for the minimum friction coefficient at $20 \mathrm{GPa}$ (Fig. 2e).

For the system at a contact pressure to $50 \mathrm{GPa}$, although the dissociation of a large amount of $\mathrm{C}_{5} \mathrm{H}_{10}$ molecules and the interaction between the two a-C layers clearly reduced both the $\mathrm{sp}^{2}$ and $\mathrm{sp}$ fractions (Fig. 8a), the most important factor was the weakening of the hydrodynamic lubrication from $\mathrm{C}_{5} \mathrm{H}_{10}$ (Fig. 8b), which led to a faster increase in the shearing strength (Fig. 8c). This induced an increase of $27.8 \%$ (from 0.36 to 0.46 ) in the friction coefficient. Therefore, for the a-C/ $C_{5} \mathrm{H}_{10}$ composite lubrication system, the hydrodynamic lubrication of $\mathrm{C}_{5} \mathrm{H}_{10}$ plays a more important role on the friction properties than the passivation of the friction interface. This can be also confirmed by the comparison of interfacial hybridized structures between the $\mathrm{C}_{5} \mathrm{H}_{10}$ lubricated (Fig. 8a) and non-lubricated conditions (see Figure S5 of Supplementary Information); the interfacial passivation under non-lubricated conditions was much better than that under lubricated conditions, but a higher friction coefficient was observed under non-lubricated conditions.

\section{DISCUSSION}

We performed reactive MD simulations using the ReaxFF force field to investigate the dependence of the friction behavior of the $\mathrm{a}-\mathrm{C} / \mathrm{C}_{5} \mathrm{H}_{10} / \mathrm{a}-\mathrm{C}$ system on the contact pressure. Systematic analysis of the hybridized structure of a-C, the MSD and dissociation of the $\mathrm{C}_{5} \mathrm{H}_{10}$ lubricant, density, residual stress, and the friction coefficient suggested the following:

- The friction coefficient of the a-C/C ${ }_{5} \mathrm{H}_{10} / \mathrm{a}-\mathrm{C}$ system depended strongly on the contact pressure. When the contact pressure was increased from 5 to 20 and $50 \mathrm{GPa}$, the friction coefficient first decreased and then increased; the minimum value of 0.36 was observed at $20 \mathrm{GPa}$.

- In particular, compared to dry conditions, introducing the
$\mathrm{C}_{5} \mathrm{H}_{10}$ lubricant into the a-C/a-C system could improve its friction properties drastically, but its working efficiency for friction reduction depended on the contact pressure. The friction coefficient showed a drastic reduction of $93 \%$ at a contact pressure of $5 \mathrm{GPa}$, while it decreased by only $19 \%$ at $50 \mathrm{GPa}$.

- Most importantly, the increase in the contact pressure induced the severe dissociation of $\mathrm{C}_{5} \mathrm{H}_{10}$ molecules, but the main scission of carbon-carbon backbones occurred at the $-\mathrm{CH}=\mathrm{CH}_{2}$ and $-\mathrm{CH}_{2}-\mathrm{CH}_{2}-$ sites, and only $42 \%$ of the molecules remained intact at a contact pressure of $50 \mathrm{GPa}$.

- High contact pressure induced the formation of highly distorted structures, leading to an increase in residual compressive stress, which was accompanied by strong structural transformation from $\mathrm{sp}^{2}-\mathrm{C}$ to $\mathrm{sp}^{3}-\mathrm{C}$.

- Although the passivation of the $s p$-hybridized structure at the interface improved as a function of contact pressure, the dominant hydrodynamic lubrication from $\mathrm{C}_{5} \mathrm{H}_{10}$ also deteriorated owing to the molecular dissociation, which could account for the change in the friction behavior.

- The present results span the range between the organic chemistry, surface science, and applied engineering, provide a scientific understanding of the alpha olefin-lubricated a-C system, and most importantly, provide effective guidance for the selection and design of lubricants and promote the development of novel a-C-lubricant composite lubrication systems for existing and potential technological implementations.

\section{METHODS}

Large-scale atomic/molecular massively parallel simulator (LAMMPS) $\operatorname{code}^{28}$ was used to perform the reactive MD simulations. Figure S6 in the Supplementary Information shows the model and the related parameters used in this calculation. The a-C structure was deposited by an atom-by-atom method ${ }^{29}$ and was set as the lower and upper mating materials. The structure was composed of 6877 carbon atoms and had an $\mathrm{sp}^{3}$ fraction of 24 at.\%, an $\mathrm{sp}^{2}$ fraction of 72 at.\%, and a density of $2.7 \mathrm{~g} /$ $\mathrm{cm}^{3} . \mathrm{C}_{5} \mathrm{H}_{10}$ was selected as a representative lubricating oil. Its surface was located $3 \AA$ away from the lower or upper a-C film, and the number of $\mathrm{C}_{5} \mathrm{H}_{10}$ molecules was fixed at 72 for each case. A three-layer model was used for the a- $\mathrm{C} / \mathrm{C}_{5} \mathrm{H}_{10} / \mathrm{a}-\mathrm{C}$ system, including a fixed layer (blue region in Figure S6), thermostatic layer (purple region in Figure S6), and free layer (remaining region in Fig. 6) to model the evolution of the friction-induced interfacial structure. In this model, the fixed layer was used to simulate the semi-infinite system, the thermostatic layer was maintained at $300 \mathrm{~K}$ using the NVE ensemble with a Berendsen thermostat ${ }^{30}$ to provide a thermal reservoir for the simulated system, and the others, including the remnant a- $\mathrm{C}$ and $\mathrm{C}_{5} \mathrm{H}_{10}$ lubricant, were totally free. A time step of $0.25 \mathrm{fs}$ was used, and the periodic boundary condition was applied along the $x$ - and $y$ directions. 
The ReaxFF potential developed by Srinivasan and Tavazza et al. ${ }^{22,23}$ was selected to describe the $\mathrm{C}-\mathrm{C}, \mathrm{C}-\mathrm{H}$, and $\mathrm{H}-\mathrm{H}$ interactions. Additional validation was also carried out by simulating the growth of a-C films using the atom-by-atom deposition approach, and the corresponding results revealed that the ReaxFF ${ }^{23}$ potential used in the present work could accurately describe the density, residual stress, hybridized structure, bond angles, and length distributions of the $\mathrm{a}-\mathrm{C}$ structures through comparison with the widely accepted AIREBO potential ${ }^{31}$ (manuscript under preparation). During the friction process, a three-step process was adopted (Figure S6): (i) geometric optimization (GO) at $300 \mathrm{~K}$ for $2.5 \mathrm{ps}$, (ii) a loading process to achieve the specified value of contact pressure $(5,20$, and $50 \mathrm{GPa}$ ) during $25 \mathrm{ps}$, and (iii) a sliding process with a fixed contact pressure (5-50 GPa) and sliding velocity $(10 \mathrm{~m} / \mathrm{s})$ along the $x$-direction for $1250 \mathrm{ps}$. A high contact pressure, such as $50 \mathrm{GPa}$, was possible for the instantaneous contact of a-C asperities during the friction process..$^{27,32}$ The evolution of the structural properties after the GO and loading processes can be found in Figure S7 of the Supplementary Information. After the friction process, the friction coefficient $(\mu)$ was calculated as follows:

$\mu=\frac{f}{\mathrm{~W}}$

where the frictional force, $f$, is calculated by summing the force acting on the fixed atoms of the lower a-C model in the sliding direction, while $W$ is the load acting on the fixed atoms of the lower a-C model in the $\mathrm{z}$ direction. The force acting on the sliding atoms was averaged every 100 MD steps, and thus a total of 50000 individual data points for the frictional force and load were obtained during 5000000 MD steps.

\section{DATA AVAILABILITY}

The data that support the findings of this study are available from the corresponding authors, specifically Professor Kwang-Ryeol Lee of the Korea Institute of Science and Technology (email: krlee@kist.re.kr) upon reasonable request.

\section{ACKNOWLEDGEMENTS}

This work was supported by the Korea Research Fellowship Program funded by the Ministry of Science and ICT through the National Research Foundation of Korea (2017H1D3A1A01055070), the Nano Materials Research Program through the Ministry of Science and IT Technology (NRF-2016M3A7B4025402), and the National Natural Science Foundation of China (51772307, 51522106).

\section{AUTHOR CONTRIBUTIONS}

X.L. and K.R.L. designed the calculations and performed the friction analysis. X.L., K.R. L., and A.W. co-wrote the manuscript. All authors participated in the discussions and manuscript preparation.

\section{ADDITIONAL INFORMATION}

Supplementary information accompanies the paper on the npj Computational Materials website (https://doi.org/10.1038/s41524-018-0111-x).

Competing interests: The authors declare no competing interests.

Publisher's note: Springer Nature remains neutral with regard to jurisdictional claims in published maps and institutional affiliations.

\section{REFERENCES}

1. Huang, J., Wang, L., Liu, B., Wan, S. \& Xue, Q. In vitro evaluation of the tribological response of Mo-doped graphite-like carbon film in different biological media. ACS Appl. Mater. Interfaces 7, 2772-2783 (2015).

2. Cui, L., Lu, Z. \& Wang, L. Probing the low-friction mechanism of diamond-like carbon by varying of sliding velocity and vacuum pressure. Carbon 66, 259-266 (2014).

3. Erdemir, A. et al. Carbon-based tribofilms from lubricating oils. Nature 536, 67-71 (2016).

4. Li, X., Guo, P., Sun, L., Wang, A. \& Ke, P. Ab initio investigation on $\mathrm{Cu} / \mathrm{Cr}$ codoped amorphous carbon nanocomposite films with giant residual stress reduction. ACS Appl. Mater. Interfaces 7, 27878-27884 (2015).
5. Griffiths, C. A. et al. A novel texturing of micro injection moulding tools by applying an amorphous hydrogenated carbon coating. Surf. Coat. Technol. 235, 1-9 (2013).

6. Holmberg, K., Andersson, P. \& Erdemir, A. Global energy consumption due to friction in passenger cars. Tribol. Int. 47, 221-234 (2012).

7. Mangolini, F. et al. Effect of silicon and oxygen dopants on the stability of hydrogenated amorphous carbon under harsh environmental conditions. Carbon 130, 127-136 (2018).

8. Roy, R. K. \& Lee, K. R. Biomedical applications of diamond-like carbon coatings: a review. J. Biomed. Mater. Res. B 83B, 72-84 (2007).

9. Dearnaley, G. \& Arps, J. H. Biomedical applications of diamond-like carbon (DLC) coatings: a review. Surf. Coat. Technol 200, 2518-2524 (2005).

10. Tasdemir, H. A. et al. Ultra-low friction of tetrahedral amorphous diamond-like carbon (ta-C DLC) under boundary lubrication in poly alpha-olefin (PAO) with additives. Tribol. Int. 65, 286-294 (2013).

11. Kano, M. Super low friction of DLC applied to engine cam follower lubricated with ester-containing oil. Tribol. Int. 39, 1682-1685 (2006).

12. Jia, Z., Xia, Y., Li, J., Pang, X. \& Shao, X. Friction and wear behavior of diamond-like carbon coating on plasma nitrided mild steel under boundary lubrication. Tribol. Int. 43, 474-482 (2010).

13. Martin, J. M. et al. Gas-phase lubrication of ta- $C$ by glycerol and hydrogen peroxide. Experimental and computer modeling. J. Phys. Chem. C. 114, 5003-5011 (2010).

14. Morina, A., Neville, A., Priest, M. \& Green, J. H. ZDDP and MoDTC interactions in boundary lubrication-the effect of temperature and ZDDP/MoDTC ratio. Tribol. Int. 39, 1545-1557 (2006).

15. Austin, L., Liskiewicz, T., Kolev, I., Zhao, H. \& Neville, A. The influence of anti-wear additive ZDDP on doped and undoped diamond-like carbon coatings. Surf. Interface Anal. 47, 755-763 (2015).

16. Okubo, H., Tadokoro, C. \& Sasaki, S. Tribological properties of a tetrahedral amorphous carbon (ta-C) film under boundary lubrication in the presence of organic friction modifiers and zinc dialkyldithiophosphate (ZDDP). Wear 332-333, 1293-1302 (2015).

17. Kano, M. et al. Ultralow friction of DLC in presence of glycerol mono-oleate (GMO). Tribol. Lett. 18, 245-251 (2005).

18. Fan, X. \& Wang, L. Graphene with outstanding anti-irradiation capacity as multialkylated cyclopentanes additive toward space application. Sci. Rep. 5, 12734 (2015).

19. Kim, D. W. \& Kim, K. W. Effects of sliding velocity and normal load on friction and wear characteristics of multi-layered diamond-like carbon (DLC) coating prepared by reactive sputtering. Wear 297, 722-730 (2013).

20. Gelinck, E. R. M. \& Schipper, D. J. Calculation of stribeck curves for line contacts. Tribol. Int. 33, 175-181 (2000).

21. Hamrock, B. J., Schmid, S. R. \& Jacobson, B. O. Fundamentals of Fluid Film Lubrication. 2nd Ed, (Marcel Dekker, New York, 2005).

22. Srinivasan, S. G., Van Duin, A. C. T. \& Ganesh, P. Development of a ReaxFF potential for carbon condensed phases and its application to the thermal fragmentation of a large fullerene. J. Phys. Chem. A 119, 571-580 (2015).

23. Tavazza, F., Senftle, T. P., Zou, C., Becker, C. A. \& Van Duin, A. C. T. Molecular dynamics investigation of the effects of tip-substrate interactions during nanoindentation. J. Phys. Chem. C. 119, 13580-13589 (2015).

24. Rabinowicz, E. Friction and Wear of Materials. 2nd Ed., New York, John Wiley \& Sons, 1995.

25. Kalin, M. \& Velkavrh, I. Non-conventional inverse-stribeck-curve behavior and other characteristics of DLC coatings in all lubrication regimes. Wear 297, 911-918 (2013).

26. McKenzie, D. R., Muller, D. \& Pailthorpe, B. A. Compressive-stress induced formation of thin-film tetrahedral amorphous carbon. Phys. Rev. Lett. 67, 773-776 (1991).

27. Ma, T. B., Hu, Y. Z. \& Wang, H. Molecular dynamics simulation of shear-induced graphitization of amorphous carbon films. Carbon 47, 1953-1957 (2009).

28. Plimpton, S. Fast parallel algorithms for short-range molecular dynamics. J. Comp. Phys. 117, 1-19 (1995).

29. Li, X., Ke, P., Zheng, H. \& Wang, A. Structure properties and growth evolution of diamond-like carbon films with different incident energies: a molecular dynamics study. Appl. Surf. Sci. 273, 670-675 (2013).

30. Berendsen, H. J. C., Postma, J. P. M., van Gunsteren, W. F., DiNola, A. \& Haak, J. R. Molecular dynamics with coupling to an external bath. J. Chem. Phys. 81, 3684-3690 (1984)

31. Stuart, S. J., Tutein, A. B. \& Harrison, J. A. A reactive potential for hydrocarbons with intermolecular interactions. J. Chem. Phys. 112, 6472-6486 (2000).

32. Ma, T. B., Wang, L. F., Hu, Y. Z., Li, X. \& Wang, H. A shear localization mechanism for lubricity of amorphous carbon materials. Sci. Rep. 4, 3662 (2014). 
Mechanism of contact pressure-induced friction at the amorphous...

$\mathrm{X} \mathrm{Li}$ et al.

Open Access This article is licensed under a Creative Commons Attribution 4.0 International License, which permits use, sharing, adaptation, distribution and reproduction in any medium or format, as long as you give appropriate credit to the original author(s) and the source, provide a link to the Creative Commons license, and indicate if changes were made. The images or other third party material in this article are included in the article's Creative Commons license, unless indicated otherwise in a credit line to the material. If material is not included in the article's Creative Commons license and your intended use is not permitted by statutory regulation or exceeds the permitted use, you will need to obtain permission directly from the copyright holder. To view a copy of this license, visit http://creativecommons. org/licenses/by/4.0/.

(c) The Author(s) 2018 